\title{
Prevalence and associated factors of Female Sexual Dysfunction among Female Population in Aksum Town, Tigray Region, Ethiopia, 2019. A Community Based Cross Sectional Study
}

Gebreslasie Gebrezgabhier

Aksum University

Haftom Desta ( $\sim$ haftomdesta496@gmail.com )

Aksum University

Tesfay Berhe

Aksum University College of Health Science

Etsay Hailu

Aksum University

Fitsum Gebrehiwot

Aksum University

Yohannes Kifle

Aksum University

\section{Research note}

Keywords: prevalence, sexual dysfunction, women, community

Posted Date: October 10th, 2019

DOI: https://doi.org/10.21203/rs.2.15838/v1

License: (c) (i) This work is licensed under a Creative Commons Attribution 4.0 International License.

Read Full License 


\section{Abstract}

Objective : Female sexual dysfunction is age related, progressive and highly prevalent, afffecting more than half of womens in general population. A Community based cross sectional study was implemented from March to April 2019 and a total of 823 participants were interviewed. Data was entered using Epidata version 3.1 and then exported to SPSS Version 20 for analysis. Bivariate and multivariate logistic regression analysis was carried out to assess the association. The p-value less than 0.05 found from multivariate logistic regression analysis was considered as statistically significant. The strength of the association was presented by odds ratio with $95 \%$ C.I and model fitness was checked by HosmerLemeshow goodness and goodness fit was 0.086 .

Result : A total of 823 women were completed the questionery with mean of Age and in this study the prevalence of Female sexual dysfunction was found to be $57.1 \%$. Factors like, old age (AOR= $4.12 ; 95 \%$ C.I:1.39, 12.22), being divorced (AOR=4.83; 95\% C.I: 2.41, 9.66), widowed (AOR=3.28; 95\% C.I:1.58, 6.80), single (AOR=6.24; 95\% C.I: 2.22, 17.53), menopause (AOR=2.11; 95\% C.I:1.06, 4.20), pill contraceptive $(A O R=0.24 ; 95 \%$ C.I: $0.06,0.95)$ were the factors associated with Female sexual dysfunction in the study area.

\section{Introduction}

Sexual dysfunction(SD) is termed as an inability to respond to sexual stimulation, or the experience of pain during the sexual act. It can also be defined as a disturbance in the subjective sense of pleasure or desire usually associated with sex, or by the objective performance[1-4]. The psychological and physiological impact of Medical problems such as diabetes mellitus, hypertention and cardiopathies are known to couse sexual dysfunctions. Complications of these chronic illness including neuropathy and vascular insufficiency have been implicated in decreased vaginal lubrication , orgasm dysfunction and decreased libido in women[5-12]. The other imporatnt thing is that. there is successful psychological and pharmacological manegement for female sexual dysfunction, so as to return their social, psychological , physical and reproductive wellbeing. Despite the available treatment, Peoples with sexual problem are rarely to be seen by their doctors.only $3.2 \%$ up to $13 \%$ are discussed with their doctors. The magnitude of sexual dysfunction in the community varies with different studies and countries. In a community survey of 436 women one over third (33\%) of respondents had one operationally defined sexual dysfunction [1321]. A prospective cohort study from Austria among 703 women shows the incidence of female sexual dysfunction; $22 \%$ reported on desire disorder, $35 \%$ arousal disorder, $39 \%$ orgasmic disorder and $12.8 \%$ reported pain disorder. A cross sectional study among 518 Turkish women showed that $48.3 \%$ women had reported female sexual dysfunction. Of the women with FSD $48.3 \%$ reported desire problem, $35.9 \%$ arousal problem, $40.9 \%$ lubrication problem, $42.7 \%$ orgasm problem, $45 \%$ satisfaction problem, and $42.9 \%$ pain problems [22-25]. A cross sectional study conducted among 586 Chinese women. The prevalence of FSD was $37.6 \%$ and domains showed; low desire in $37.6 \%$ of women, adesire disorder in $23.6 \%$, an arousal problem in $25.4 \%$, a lubrication problem in $36.8 \%$, an orgasm problem in $30.6 \%$, and a pain problem in 21.8\%.[27]Another cross sectional study from Hong Kong reported that $37.9 \%$ of women 
had one form of sexual dysfunction [26-28]. A study conducted among 2409 Iranian women showed that $31.5 \%$ of participants reported at least one form of sexual dysfunction. The main domain of FSD observed was orgasm disorder (37\%), followed by desire disorder (35\%), lubrication disorder (33.7\%), satisfaction disorder (31.5), arousal disorder (30\%), and pain disorder (26.7\%) [15]. Another cross sectional study inurban Iran, among 1456 sexually active women, more than $52 \%$ of participants had experienced at least one type of sexual difficulty [29]. As per the study conducted in five Egyptian cities, $68.9 \%$ of women participants were reported one or more sexual dysfunction. [30]. A cross sectional study from Ghana reported that, the prevalence of female sexual dysfunction was $72.8 \%$ [14].

\section{Methods}

\section{Study setting}

The study was carried out in Aksum Town, Central zone of Tigray regional state of Ethiopia. Currently, Aksum serves as the capital of the central Zone of Tigray regional state. Based on the 2007 national census by the Central Statistical Agency, the town has a total population of 63,979 , of whom 30,441 are men and 33,538 women.

\section{Study design and population}

This study was done using a Community-based cross-sectional study design from March to April 2019. Women were lived in Aksum Town and who were ages 18 years and above were included in the study and those with physical or mental illness were excluded from the study.

\section{Sample size and sampling technique}

The sample size of this study was calculated using a single proportion formula as follow:

$$
\mathrm{n}=(\mathrm{z} \alpha \square) \mathrm{p}(1-\mathrm{p}) / \mathrm{d} \square
$$

Where

$\mathrm{n}=$ number of the study subjects (sample size)

$\mathrm{Z}=$ standardized normal distribution value for the 95\% confidence level (1.96)

$\mathrm{d}=$ Margin of error taken (0.05) 
$\mathrm{p}=50 \%$ since there is no study conducted in the study area.Based on the above assumptions, by using of 2 design effect and 10\% non-response, the final sample size becomes 845.

In this study Two Kebeles were randomly selected from the Five Kebeles of Aksum Town. Later, systematic sampling technique was being employed for selection of the participants. Study subjects were selecting every 7 House-holds until the sampled population fills. Selection of the first sample was taken through simple random lottery method.

\section{Operational definition}

- Female sexual dysfunction; are those women who are found to score $<23$ from FSFI was considered to have female sexual dysfunction. [31]

- Physically exercise: when subjects engaged in moderate activities at least 5 times per week, duration 30 minutes and/or vigorous activities at least 3 times per week, duration 20 minutes.[32]

\section{- SUBSTANCE USE}

- Current use: using at least one of a specific substance for non-medical purpose within the last three months (alcohol, khat, tobacco, others).

- Ever use of substance: using at least one of any specific substance for non-medical purpose at least once in life time (alcohol, khat, tobacco, others). [33]

- Physical illness: those respondents who were responded having chronic physical illness which was diagnosed before from any private and public health institution.[32]

- Social support: Assessed by Oslo social support scale (OSSS -3) was classified in to three levels.[34]

- Menopause:if women's age is $\geq 40$ and lack of menses for 12 straight months in the absence of pregnancy were considered as menopause. [35]

- Depression: Those respondents who are found to score $\geq 10$ in PHQ-9 were classified as having depression.[36].

- Psychological distress; assessed by Kessler psychological distress scale(K-10). [37]

- Kebelles: Small administrative unit in Ethiopia.

\section{Data collection tools and procedure}

A structured, pretested and quantitative interviewer administered questionnaire was adopted by reviewing different literatures. The questionnaire was prepared in English and 
then translated in to Tigrigna version and then translated back to English for its consistency and completeness.

To maintain data quality, data were collected by Female BSc psychiatric nurses and MSc in Psychiatry supervisors. Both of data collectors and supervisors were trained for two days to ensure the quality of data including clarification of questions to make simple and easily understandable, to use recommended ways of sampling technique and to inform the study subjects based on the consent. Seven female BSc psychiatric nurseswere assigned to collect data by face to face interview. Four MSc in Psychiatry supervised the data collector's and they had been communicated daily with the authors. The questionnaire was tested for its clarity, consistency and unambiguous and appropriate modification had done based on findings. Supervisors and authors were strictly followed the data collection process and filled questionnaire were reviewed daily for completeness and consistency.

\section{Data processing and analysis procedures}

The data were entered, cleaned and coded using Epi-data version 3.1 and data analysis was done using SPSS version 20. It was described using frequency tables and descriptive statistics. The association between dependent and independent factors was analyzed using binary logistic regression analysis with crude Odds Ratio along with 95\% confidence interval, then these factors with $\mathrm{P}$-value $<0.25$ analyzed using multivariate logistic regression analysis to determine the associated factors with Female Sexual Dysfunction and to control confounding factors. In multivariate analysis, variables having p-value less than 0.05 and adjusted odds ratio with $95 \%$ CI were considered as significantly associated with the outcome variables.

\section{Results}

\section{Socio-demographic characteristics of respondents}

In this study; majority of the participants were Tigrean (98.1\%), Ethiopian orthodox religion followers $(82.7 \%)$, and married (73.8\%). More than thirty percents of the participants were in the age group of 28-37 $(32.7 \%)$, about thirty seven percents were unable to read and write, about half of the respondents were house wife, more than half were below poverty line, nearly seventy percents were currently in active menstruation, about half of the respondents had 1-5 children, about sixty percent were not used contraceptive (Table 1).

Table 1 The socio-demographic status of study participants in Aksum city, Tigray, Ethiopia, 2019. 


\begin{tabular}{|c|c|c|c|}
\hline Variables & Category & frequency & Percent \\
\hline \multirow[t]{5}{*}{ Age } & $18-27$ & 122 & 14.8 \\
\hline & $28-37$ & 269 & 32.7 \\
\hline & $38-47$ & 156 & 19.0 \\
\hline & $48-57$ & 150 & 18.2 \\
\hline & $>57$ & 126 & 15.3 \\
\hline \multirow[t]{2}{*}{ Ethnicity } & Tigrean & 807 & 98.1 \\
\hline & Other & 16 & 1.9 \\
\hline \multirow[t]{3}{*}{ Religion } & orthodox Christian & 681 & 82.7 \\
\hline & Muslim & 127 & 15.4 \\
\hline & protestant Christian & 15 & 1.8 \\
\hline \multirow[t]{4}{*}{ Marital status } & Married & 607 & 73.8 \\
\hline & Divorced & 81 & 9.8 \\
\hline & Widowed & 102 & 12.4 \\
\hline & Single & 33 & 4.0 \\
\hline \multirow[t]{4}{*}{ Educational status } & unable to read and write & 306 & 37.2 \\
\hline & $1-8$ & 194 & 23.6 \\
\hline & $9-12$ & 150 & 18.2 \\
\hline & collage and above & 173 & 21.0 \\
\hline \multirow[t]{4}{*}{ Job } & Government employee & 132 & 16.0 \\
\hline & Merchant & 227 & 27.6 \\
\hline & House wife & 420 & 51.0 \\
\hline & Other & 44 & 5.3 \\
\hline \multirow[t]{2}{*}{ Income } & below poverty line & 471 & 57.2 \\
\hline & above poverty line & 352 & 42.8 \\
\hline \multirow[t]{2}{*}{ menstrual status } & On Menopause & 252 & 30.6 \\
\hline & On menstrual cycle & 571 & 69.4 \\
\hline \multirow[t]{2}{*}{ Number of children } & None & 145 & 17.6 \\
\hline & $1-5$ & 425 & 51.6 \\
\hline
\end{tabular}




\begin{tabular}{llll} 
& $6-10$ & 163 & 19.8 \\
\cline { 2 - 3 } Contraceptive use & No & 90 & 10.9 \\
\cline { 2 - 3 } & Pill & 501 & 60.9 \\
\cline { 2 - 3 } & Depo & 51 & 6.2 \\
\cline { 2 - 3 } Medical illness & Implant & 146 & 17.7 \\
\cline { 2 - 3 } & Intra uterine device & 13 & 13.6 \\
\cline { 2 - 3 } & No & 619 & 1.6 \\
\cline { 2 - 3 } & DM & 109 & 75.2 \\
\cline { 2 - 4 } & Hypertension & 24 & 13.2 \\
\cline { 2 - 3 } & Other & 57 & 2.9 \\
\hline
\end{tabular}

\section{Substance use conditions of respondents}

Out of the total study participants, 403(49.3\%) hadused substance atleast once during their life time and $399(48.5 \%)$ were taking atleast one type of substances in the last three month before their study participation .

\section{Psycho-social condtions of study participants}

Among study participants, about $44 \%$ were reported poor social support, more than $60 \%$ of respondents had depression, and $23.5 \%$ had severe mental distress (Table 2).

Table 2 psycho-social conditions ofstudy participants in Aksum city, Tigray, Ethiopia, 2019. 


\begin{tabular}{llll} 
Variables & Category & Frequency & Percent \\
\hline Level of social support & poor social support & 362 & 44 \\
\cline { 2 - 4 } & moderate social support & 305 & 37.1 \\
\cline { 2 - 4 } & strong social support & 156 & 18.9 \\
\hline Depression & no depression & 518 & 62.9 \\
\cline { 2 - 4 } & Depression & 305 & 37.1 \\
\hline Psychological distress & likely well & 494 & 60.0 \\
\cline { 2 - 4 } & mild mental disorder & 69 & 8.4 \\
\cline { 2 - 4 } & moderate mental disorder & 67 & 8.1 \\
\cline { 2 - 4 } & severe mental disorder & 193 & 23.5
\end{tabular}

\section{Medication related conditions of study participants}

In this study thirty six women were reported history of sexual disorder prior to the current episode, twenty of them were reported medication use. About $37 \%$ of respondents thought that psychological support is important for sexual dysfunction.

\section{Prevalence of sexual dysfunction}

The prevalence of sexual dysfunction among women residents in Aksum city was found to be $57.1 \%$ (95\% C.I: 53.7, 60.6).

\section{Factors associated with female sexual dysfunction}

After the bivariate logistic regression, multivariate logistic regression was employed to identify the independent predictors of sexual function in female. Accordingly, older age (AOR=4.12; 95\% C.l:1.39, 12.22), being divorced (AOR=4.83; 95\% C.I: 2.41, 9.66), widowed (AOR=3.28; 95\% C.I:1.58, 6.80), single ( $A O R=6.24 ; 95 \%$ C.I: $2.22,17.53)$, menopause (AOR=2.11; 95\% C.l:1.06,4.20), pill contraceptive use $(A O R=0.24 ; 95 \%$ C.I: 0.06, 0.95), and depression ( $A O R=2.57 ; 95 \%$ C.I: $1.58,4.20)$ were found to be significantly associated with female sexual dysfunction(Table 3 ).

Table 3: bivariate and multivariate logistic regression analysis of factors associated with female sexual dysfunctions, among women respondents ofAksum city, Tigray, Ethiopia, 2019. 
Variable

\section{Variable}

Category $\begin{array}{lll}\text { Sexual } & \text { COR } & \text { AOR }\end{array}$ dysfunction

No Yes

\begin{tabular}{|c|c|c|c|c|c|}
\hline \multirow[t]{5}{*}{ Age } & $18-27$ & 63 & 59 & 1 & 1 \\
\hline & $28=37$ & 173 & 96 & $.59(.38,0.91)$ & $.0 .88(.0 .50,1.55)$ \\
\hline & $38-47$ & 65 & 91 & $\begin{array}{l}1.49(0.93 \\
2.41)\end{array}$ & $1.58(0.82,3.03)$ \\
\hline & $48-57$ & 41 & 109 & $\begin{array}{l}2.84(1.71 \\
4.70)\end{array}$ & $1.29(0.55,3.01)$ \\
\hline & $>57$ & 11 & 115 & $\begin{array}{l}11.16(5.47, \\
22.78)\end{array}$ & $\begin{array}{l}4.12(1.39,12.22) \\
0.01^{*}\end{array}$ \\
\hline
\end{tabular}

Marital status

\begin{tabular}{lll} 
Married & 322 & 286 \\
\hline Divorced & 13 & 69
\end{tabular}

1

5.98(3.23, $\quad 4.83(2.41,9.66)$ ** 11.04)

\begin{tabular}{lccll|} 
Widowed & 11 & 89 & $\begin{array}{l}9.11(4.77, \\
17.38)\end{array}$ & $\mathbf{3 . 2 8}(1.58,6.80) *$ \\
\hline Single & 7 & 26 & $\begin{array}{l}4.18(1.79, \\
9.78)\end{array}$ & $\mathbf{6 . 2 4}(2.22,17.53)$ *
\end{tabular}

Numberof children

Educational status

\begin{tabular}{|c|c|c|c|c|}
\hline & $1-8$ & 77 & 117 & $\begin{array}{l}1.28(0.84 \\
1.93)\end{array}$ \\
\hline & $9-12$ & 77 & 73 & $.80(0.51,1.23)$ \\
\hline & Collage and above & 79 & 94 & 1 \\
\hline \multirow[t]{2}{*}{$\begin{array}{l}\text { Menstrual } \\
\text { status }\end{array}$} & Menopause+ & 42 & 210 & $\begin{array}{l}5.98(4.13 \\
8.66)\end{array}$ \\
\hline & Menstrual+ & 311 & 260 & 1 \\
\hline \multirow[t]{2}{*}{$\begin{array}{l}\text { Job of } \\
\text { respondents }\end{array}$} & $\begin{array}{l}\text { Government } \\
\text { employee }\end{array}$ & 60 & 72 & 1 \\
\hline & Merchant & 101 & 126 & $\begin{array}{l}1.04(0.67 \\
1.60)\end{array}$ \\
\hline
\end{tabular}

Can't read and 74

71

$.37(0.21,0.65)$

0.49(0.23,1.05)

1-5

19

229

$.45(0.27,0.74)$

$0.80(0.42,1.50)$

6-10

58

$105.70(0.40,1.22)$

$0.71(0.35,1.44)$

$>10$

25

65

1

1

$120 \quad 186$

1.30(0.89, $1.90)$

0.58(0.33, 1.03)

$0.98(.55,1.73)$

$0.84(.0 .48,1.48)$

1

$2.11(1.06,4.20)$ * 1

1

$1.14(0.64,2.03)$ 


\begin{tabular}{|c|c|c|c|c|c|}
\hline & House wife & 179 & 241 & $\begin{array}{l}\text { 1.12(0.76, } \\
1.66)\end{array}$ & $\begin{array}{l}1.15(0.66 \\
1.99)\end{array}$ \\
\hline & Other & 13 & 31 & $\begin{array}{l}1.98(0.95 \\
4.13)\end{array}$ & $1.68(0.66,4.32)$ \\
\hline \multirow{5}{*}{$\begin{array}{l}\text { Chronic medical } \\
\text { illness }\end{array}$} & No & 307 & 312 & 1 & 1 \\
\hline & DM & 23 & 86 & $\begin{array}{l}3.68(2.26 \\
5.98)\end{array}$ & $1.46(0.77,2.75)$ \\
\hline & CHD & 4 & 20 & $\begin{array}{l}4.92(1.66 \\
14.56)\end{array}$ & $2.70(0.75,9.81)$ \\
\hline & Hypertension & 15 & 42 & $\begin{array}{l}2.75(1.50 \\
5.07)\end{array}$ & $1.43(0.69,2.96)$ \\
\hline & Other & 4 & 10 & $\begin{array}{l}2.46(0.76 \\
7.93)\end{array}$ & $\begin{array}{l}2.14(0.50 \\
9.18)\end{array}$ \\
\hline \multirow[t]{5}{*}{$\begin{array}{l}\text { Contraceptive } \\
\text { use }\end{array}$} & No & 157 & 344 & $\begin{array}{l}1.37(0.44 \\
4.25)\end{array}$ & $0.71(0.21,2.43)$ \\
\hline & Pill & 34 & 17 & $.31(0.09,1.10)$ & $0.24(0.06,0.95)$ * \\
\hline & Depo & 90 & 56 & $.39(0.12,1.25)$ & $0.38(0.11,1.33)$ \\
\hline & Implant & 67 & 45 & $.42(0.13,1.36)$ & $0.39(0.11,1.37)$ \\
\hline & IUD & 5 & 8 & 1 & 1 \\
\hline \multirow{2}{*}{$\begin{array}{l}\text { Current use of } \\
\text { chat }\end{array}$} & No & 343 & 466 & 1 & 1 \\
\hline & Yes & 10 & 4 & $3.81(2.5,5.80)$ & $.46(0.12,1.83)$ \\
\hline \multirow[t]{3}{*}{$\begin{array}{l}\text { Level of social } \\
\text { support }\end{array}$} & poor social support & 152 & 210 & $\begin{array}{l}0.86(0.59 \\
1.27)\end{array}$ & $0.63(0.38,1.03)$ \\
\hline & $\begin{array}{l}\text { moderate social } \\
\text { support }\end{array}$ & 141 & 164 & $\begin{array}{l}.0 .73(0.49 \\
1.08)\end{array}$ & $0.79(0.49,1.28)$ \\
\hline & $\begin{array}{l}\text { strong social } \\
\text { support }\end{array}$ & 60 & 96 & 1 & 1 \\
\hline \multirow{2}{*}{$\begin{array}{l}\text { Depression } \\
\text { status }\end{array}$} & No & 270 & 248 & 1 & 1 \\
\hline & Yes & 83 & 222 & $2.91(2.15,3.95)$ & $\begin{array}{l}2.57(1.58 \\
4.20)^{\star \star}\end{array}$ \\
\hline \multirow{4}{*}{$\begin{array}{l}\text { Psychological } \\
\text { distress }\end{array}$} & likely well & 237 & 257 & 1 & 1 \\
\hline & $\begin{array}{l}\text { mild mental } \\
\text { disorder }\end{array}$ & 33 & 36 & $\begin{array}{l}1.01(0.61 \\
1.67)\end{array}$ & $0.67(0.35,1.27)$ \\
\hline & $\begin{array}{l}\text { moderate mental } \\
\text { disorder }\end{array}$ & 29 & 38 & $\begin{array}{l}1.21(0.72 \\
2.02)\end{array}$ & $0.50(0.24,1.04)$ \\
\hline & severe mental & 54 & 139 & 2.37(1.65, & $0.93(0.53,1.63)$ \\
\hline
\end{tabular}


** $P$ value $<0.05, * p$ value $<0.01$

Hosmer-lemshow goodness of fit is 0.086

\section{Discussion}

The prevalence of sexual dysfunction among women participated in this study was found to be $57.1 \%$. The magnitude of prevalence in this study was higher than studies found in Brazil (49\%) [24], Korea (43.1\%) [26], and Iran (52\%) [29]. This discordance might be attributed to the difference in survey (internet survey was used in the Korea), difference in socioeconomical status, and sample size of these study populations. However, the prevalence of this study was lower than studies found in Egypt (68.9\%) [30], and Ghana (72.8) [14]. This variation may be due to the study in Egypt was ccovered large study areas(conducted in more than five Egyptian cities), socio-cultural difference and/or the difference in sampl size .

In this study advanced age was significantly associated with FSD. The result was suported by studies conducted in Brazil and Hong-kong $[24,28]$. This may be due to the fact that as age goes increases a number of change in sexual, hormonal, and physiological function takes place. In addition it may be cofound with number of illness faced as age got increased.

This study showed that being divorced, widowed, and single had a significant association with FSD. The study done in Iran and Tukey supported that divorced women had significantly higher sexual dysfunction [15, 23]. This may be attributed to the social and economical burdens must women faced when they are alone. Hence, the burden is increased among developing countries in which majority of the women is dependent on their husband. The psychological stress associated with being divorced and may be another possible reason.

Acording to this study menopuse women had significantly higher sexual dysfunction as compared with those women in active menstruate. Smilar results have been found inIran [15]. This may be due to the hormonal changes oocured with menopause.

This study indicated that women who had depression were more likely to have SD than women without depresion. This result was consistent with a studies done in Colombia and Korea $[25,26]$. This may be attributed to the decrease in nor-epinephrine and serotonin associated with depression are also associated with sexual inhibition. The psychological effect of depression may also affect sexual functions of a women. Loss of interest, cardinal symptoms of the illness, may include loss of sexual function 
This study showed that women with pill contraceptive were least likely to have sexual dysfunction. This was consistent with a study found in Iran [29]. The possible reason for this may be the hormonal effects of the contraceptive\& cultural \& religious difference.

\section{Conclusions}

This study indicated that the magnitude of sexual dysfunction among women who were participated in this study was found high. Older age, being single, divorced, widowed, menopause, and having depression were association with FSD. So women especially those who are with advanced age, single divorced, widowed, menopause, and depressed should have carefully evaluate for sexual dysfunction.

\section{Limitations Of The Study}

The cross-sectional nature of the study makes it difficult to determine the direction of causality, therefore, further analytical study is needed to understand the direct causal relationships of variables.

\section{Abbreviations}

BSc ;Bachelor of Sciences

CHD :Chronic Heart Disease

C.I : Confidence Interval

DM :Diabetes Mellitus

FSD :Female Sexual Dysfunction

IUD :Intra uterine Device

MSc :Master of Sciences

OSSS :Oslo social support scale

SD : Sexual Dsyfunction

SPSS: Statistical Package for Social Science

VIF :Variance Inflation Factors

\section{Declarations}

Ethics approval and consent to participate 
The study was approved by Aksum University, College of Health science, Research Ethics Committee. Permission letter was also obtained from Aksum City health office and was presented to all participants. Written consent was obtained after the potential participants were informed of the study's objectives and reading the information sheet. Only women who gave consent to participate were included in the study. All participants were also informed that they could withhold or withdraw from participation at any time, without any negative consequences. Interviews were conducted in private that guarantee optimum privacy. Confidentiality and privacy of the study were maintained during data collection, analysis, and reporting.

\section{Consent for publication}

Not applicable

\section{Availability of data and materials}

The datasets in which conclusion taken is available in the form of Microsoft Excel. It is available on requesting

\section{Competing interests}

The authors declare that they have no competing interests.

\section{Funding}

This work was funded by Aksum University College of Health Science. The funded organization financed for data collection process including analysis and interpretation.

\section{Authors' contributions}

GG wrote the proposal, participated in data collection, analyzed the data, and drafted the paper. HD , TB , EH , FG and Yk approved the proposal, participated in data analysis and revised subsequent drafts of the paper. All authors read and approved the final manuscript

\section{Acknowledgements}

Our heartfelt thank goes to Aksum University for financial support. We are thankful to Aksum Town for their positive responses to facilitate the study and all study participants 
who voluntarily participated in this study.

Author's information

GG :MSc , Department of psychiatry, College of Health Science,AksumUniversity, Aksum, Ethiopia

HD:MSc , Department of psychiatry, College of Health Science,AksumUniversity, Aksum, Ethiopia

TB: MPH, Department of public health College of Health Science, Aksum University, Aksum, Ethiopia

EH:MSc , Department of psychiatry, College of Health Science,AksumUniversity, Aksum, Ethiopia

FG:MSc , Department of psychiatry, College of Health Science,AksumUniversity, Aksum, Ethiopia

YK:MSc , Department of psychiatry, College of Health Science,AksumUniversity, Aksum, Ethiopia

\section{References}

1. Frances A, Pincus HA, First M: Diagnostic and statistical manual of mental disorders: DSM-IV: American Psychiatric Association Washington DC; 1994.

2. Organization WH: ICD-10: International statistical classification of diseases and health-related problems. Geneva: WHO 1992.

3. Wright JJ, Oâ€ ${ }^{\mathrm{TM}}$ Connor KM: Female sexual dysfunction. Medical Clinics, 99(3):607628.

4. Basson R, Berman J, Burnett A, Derogatis L, Ferguson D, Fourcroy J, Goldstein I, Graziottin A, Heiman J, Laan E: Report of the international consensus development conference on female sexual dysfunction: definitions and classifications. The Journal of urology 2000, 163(3):888-893.

5. Doruk H, Akbay E, Cayan S, Bozlu M, Acar D: Effect of diabetes mellitus on female sexual function and risk factors. Archives of andrology 2005, 51(1):1-6.

6. Grimm Jr RH, Grandits GA, Prineas RJ, McDonald RH, Lewis CE, Flack JM, Yunis C, Svendsen K, Liebson PR, Elmer PJ: Long-term effects on sexual function of five antihypertensive drugs and nutritional hygienic treatment in hypertensive men and women: Treatment of Mild Hypertension Study (TOMHS). Hypertension 1997, 29(1):8-14.

7. Briere J, Elliott DM: Prevalence and psychological sequelae of self-reported childhood physical and sexual abuse in a general population sample of men and women. Child abuse \& neglect 2003, 27(10):1205-1222.

8. Dunn KM, Croft PR, Hackett GI: Association of sexual problems with social, psychological, and physical problems in men and women: a cross sectional population survey. Journal of Epidemiology \& Community Health 1999, 53(3):144-148.

9. Hayes RD, Dennerstein L, Bennett CM, Sidat M, Gurrin LC, Fairley CK: Risk factors for female sexual dysfunction in the general population: Exploring factors associated 
with low sexual function and sexual distress. The journal of sexual medicine 2008, 5(7):1681-1693.

10. Bancroft J: Sexual effects of androgens in women: some theoretical considerations. Fertility and Sterility 2002, 77:55-59.

11. Higgins A, Nash M, Lynch AM: Antidepressant-associated sexual dysfunction: impact, effects, and treatment. Drug, healthcare and patient safety, 2:141.

12. Laumann EO, Paik A, Rosen RC: Sexual dysfunction in the United States: prevalence and predictors. Jama 1999, 281(6):537-544.

13. Vroege JA, Gijs L, Hengeveld MW: Classification of sexual dysfunctions: towards DSM-V and ICD-11. Comprehensive psychiatry 1998, 39(6):333-337.

14. Amidu N, Owiredu WK, Woode E, Addai-Mensah O, Quaye L, Alhassan A, Tagoe EA: Incidence of sexual dysfunction: a prospective survey in Ghanaian females. Reproductive Biology and Endocrinology, 8(1):106.

15. Safarinejad M: Female sexual dysfunction in a population-based study in Iran: prevalence and associated risk factors. International Journal of Impotence Research 2006, 18(4):382.

16. Trudel G: Sexuality and marital life: Results of a survey. Journal of Sex \&Marital Therapy 2002, 28(3):229-249.

17. Witting K, Santtila P, Alanko K, Harlaar N, Jern P, Johansson A, Von Der Pahlen B, Varjonen M, Â...lgars M, Sandnabba NK: Female sexual function and its associations with number of children, pregnancy, and relationship satisfaction. Journal of Sex \& Marital Therapy 2008, 34(2):89-106.

18. Lewis RW, Fuglâ€₫Meyer KS, Bosch R, Fuglâ€₫Meyer AR, Laumann EO, Lizza E, Martinâ€\Morales A: Epidemiology/risk factors of sexual dysfunction. The journal of sexual medicine 2004, 1(1):35-39.

19. Seid A, Gerensea H, Tarko S, Zenebe Y, Mezemir R: Prevalence and determinants of erectile dysfunction among diabetic patients attending in hospitals of central and northwestern zone of Tigray, northern Ethiopia: a cross-sectional study. $B M C$ endocrine disorders, 17(1):16.

20. Bancroft J: The medicalization of female sexual dysfunction: The need for caution. Archives of sexual behavior 2002, 31(5):451-455.

21. Osborn M, Hawton K, Gath D: Sexual dysfunction among middle aged women in the community. Br Med J (Clin Res Ed) 1988, 296(6627):959-962.

22. Ponholzer A, Roehlich M, Racz U, Temml C, Madersbacher S: Female sexual dysfunction in a healthy Austrian cohort: prevalence and risk factors. European urology 2005, 47(3):366-375.

23. Oksuz E, Malhan S: Prevalence and risk factors for female sexual dysfunction in Turkish women. The Journal of urology 2006, 175(2):654-658.

24. Abdo CHN, Oliveira Jr W, Moreira Jr ED, Fittipaldi JoAnS: Prevalence of sexual dysfunctions and correlated conditions in a sample of Brazilian womenâ€"results of the Brazilian study on sexual behavior (BSSB). International Journal of Impotence Research 2004, 16(2):160.

25. Echeverry MC, Arango A, Castro B, Raigosa G: Study of the prevalence of female sexual dysfunction in sexually active women 18 to 40 years of age in Medellin, Colombia. The journal of sexual medicine, 7(8):2663-2669.

26. Song SH, Jeon H, Kim SW, Paick JS, Son H: The prevalence and risk factors of female sexual dysfunction in young Korean women: An internetâ€nbased survey. The journal of sexual medicine 2008, 5(7):1694-1701.

27. Ma J, Pan L, Lei Y, Zhang A, Kan Y: Prevalence of female sexual dysfunction in urban chinese women based on cutoff scores of the Chinese version of the female 
sexual function index: a preliminary study. The journal of sexual medicine, 11(4):909919.

28. Zhang H, Yip PS: Female sexual dysfunction among young and middleâ€包ed women in Hong Kong: Prevalence and risk factors. The journal of sexual medicine, 9(11):2911-2918.

29. Goshtasebi A, Vahdaninia M, Rahimi Foroshani A: Prevalence and potential risk factors of female sexual difficulties: An urban Iranian populationâ€nbased study. The journal of sexual medicine 2009, 6(11):2988-2996.

30. Elnashar A, Elâ€ロDien Ibrahim M, Elâ€ロDesoky M, Ali O, Elâ€₫Sayd Mohamed Hassan M: Female sexual dysfunction in Lower Egypt. BJOG: An International Journal of Obstetrics \& Gynaecology 2007, 114(2):201-206.

31. Wiegel M, Meston C, Rosen R: The female sexual function index (FSFI): crossvalidation and development of clinical cutoff scores. Journal of Sex \& Marital Therapy 2005, 31(1):1-20.

32. Organization WH: International travel and health: situation as on 1 January 2010: World Health Organization.

33. Humeniuk R, Ali R, Babor TF, Farrell M, Formigoni ML, Jittiwutikarn J, De Lacerda RB, Ling W, Marsden J, Monteiro M: Validation of the alcohol, smoking and substance involvement screening test (ASSIST). Addiction 2008, 103(6):1039-1047.

34. Abiola T, Udofia O, Zakari M: Psychometric properties of the 3-item oslo social support scale among clinical students of Bayero University Kano, Nigeria. Malaysian Journal of Psychiatry, 22(2):32-41.

35. Goodman N, Cobin R, Ginzburg S, Katz I, Woode D: American Association of Clinical Endocrinologists medical guidelines for clinical practice for the diagnosis and treatment of menopause. Endocrine practice, 17(Supplement 6):1-25.

36. Lasa L, Ayuso-Mateos J, Vazquez-Barquero J, DÄ \pm ez-Manrique F, Dowrick C: The use of the Beck Depression Inventory to screen for depression in the general population: a preliminary analysis. Journal of affective disorders 2000, 57(1-3):261265.

37. Andrews G, Slade T: Interpreting scores on the Kessler psychological distress scale (K10). Australian and New Zealand journal of public health 2001, 25(6):494-497. 